OPEN ACCESS

Edited by:

Jinyang Fan,

Chongqing University, China

Reviewed by:

Dingyi Hao,

Anhui University of Science and

Technology, China

Honghua Song,

China University of Mining and

Technology, China

*Correspondence: Jing Shengguo pobo@163.com

Specialty section:

This article was submitted to

Geohazards and Georisks,

a section of the journal

Frontiers in Earth Science

Received: 19 November 2021

Accepted: 10 January 2022

Published: 25 January 2022

Citation:

Zhili S, Shengguo J, Wenbing $X$ and Qingteng $T$ (2022) Research on Coal Acoustic Emission Characteristics and

Damage Evolution During

Cyclic Loading.

Front. Earth Sci. 10:818452.

doi: 10.3389/feart.2022.818452

\section{Research on Coal Acoustic Emission Characteristics and Damage Evolution During Cyclic Loading}

\author{
Su Zhili ${ }^{1}$, Jing Shengguo ${ }^{2 *}$, Xie Wenbing ${ }^{1,2}$ and Tang Qingteng ${ }^{1}$ \\ ${ }^{1}$ State Key Laboratory of Coal Resources and Safe Mining, China University of Mining and Technology, Xuzhou, China, ${ }^{2}$ School of \\ Mines, China University of Mining and Technology, Xuzhou, China
}

The acoustic emission, energy, and damage evolution of coal samples for three kinds of uniaxial cyclic loading and unloading are deeply analyzed in this study. The evolution of total absorption energy, elastic strain energy, and dissipated energy of coal samples is related to the stress path, and the increasing amplitudes cycle loading has an obvious damage effect on coal samples. During the loading stage, the acoustic emission phenomenon is most active when loading is increasing and the Felicity and post-Kaiser phenomena appear. The acoustic emission phenomenon during constant loading does not obviously change, but rather becomes active with the increase of the equivalent load. The damage to the coal sample shows nonlinear change increasing loading and unloading and shows linear change for other stress paths. Compared to waveforms with stepwise increasing amplitudes cyclic loading, the failure process of the coal sample is more closely related to the size of the external load, which indicates that reasonable hydraulic design is beneficial to the stability of the confining pressure in the chamber of an underground pumped storage hydropower station.

Keywords: coal sample, cyclic loading, rock damage, rock acoustic emission, energy evolution

\section{INTRODUCTION}

In the current energy transition from fossil energy to environmental energy, the proportion of energy from new sources, such as solar, wind, and hydropower, continues to hit new highs. However, these new types of energy generation are greatly affected by the weather, and so cannot provide energy consistently. Energy storage technology is one solution to the instability of these new energy sources (Bilgili et al., 2015). At present, energy storage technologies are mainly divided into chemical battery storage, compressed air energy storage (CAES), and underground pumped storage hydropower stations (UPSHs) (Rahman et al., 2020; Fan et al., 2020a). These technologies are applicable to different times and spaces. CAES requires strict geological conditions to meet the requirements of impermeability for high pressure air, which is why it is mainly used in rock salt mine caves (Fan et al., 2019). In contrast, a UPSH is more flexible in terms of technology and has lower environmental requirements (Gaudard and Madani 2019). China in particular has long relied on coal as its main energy source, and it has many abandoned mines, some of which are located near the country's main wind and solar power sources. Using these abandoned mines to build UPSHs can not only solve the problem of abandoned mines destroying the environment, but also contribute to the sustainable development of local economies (Menendez et al., 2019a; Menendez et al., 2019b). A UPSH consists of two reservoirs. The upper reservoir is located on the surface of the ground, which is an industrial square (an area protecting the ground factories of coal mines) for coal mining, and the lower 
reservoir is located underground. The lower reservoirs are usually built 1) to excavate and secure additional caverns, 2) to make use of existing roadways, or 3) to excavate new roadways (Madlener and Specht 2013). During the operation of a coal mine pumped storage power station, the discharge and impounded processes of water are repeated, which causes periodic loading and unloading of the surrounding rock inside the power station, leading to a change in the mechanical properties of the mine's surrounding rock. Determining how to maintain the stability of the rock surrounding the underground reservoir during the operation of an energy storage power station is an urgent problem that needs to be solved.

In order to solve the problem of surrounding rock stability, scholars have performed a great amount of research. Menéndez et al. (2019c) studied the influence of the pumping and storage process on the stability of the rock surrounding a UPSH in northern Spain. The cyclic loading and unloading pressures generated by the confining pressure of the UPSH chamber had an irreversible impact on the stability of the chamber's surrounding rock. Fu et al. (2020) studied the characteristic stress and mechanical properties of marble cracks for three different cyclic loading stress paths, and found that the crack initiation stress of the marble first increased, and then decreased, with the increasing number of cycles. Based on these test results, Fu put forward the CVFE constitutive model and applied it to Realistic Failure Process Analysis software (RFPA2D), and then studied the stability of the surrounding rock in the chamber. From their research, it was apparent that the load types of the surrounding rock of the CAES or UPSH were mainly cyclic. These cyclic loads could be classified into four classes according to the shape of the load-time curve (Heap et al., 2009; Jia et al., 2018; Liu et al., 2018; Peng et al., 2020): constant amplitude cyclic loading, incremental cyclic loading, variable amplitude cyclic loading, and random cyclic loading.

Using different circulation paths, scholars have carried out laboratory experiments on the mechanical properties of different lithological rocks; usually granite, marble, sandstone, rock salt, and coal (Wang et al., 2021a; Li et al., 2021). Tang et al. (2020) used acoustic emission monitoring technology to study the crack development law of the post-peak of granite under a cyclic load and found that the strain concentration zone expanded centrally along both sides of the crack, the crack opening degree increased with the increasing number of cyclic loads, and the acoustic emission B value increased first and then decreased. Liu et al. (2021) studied the acoustic emission characteristics of weakly cemented rock mass under different triaxial stress paths are studied. Liu et al. (2012) studied the influence of cyclic frequency on the damage degree of sandstone, and found that with an increase in frequency, the initial stiffness of the sandstone was higher and the number of cycles it withstood before failing was also higher. Rocks with different lithologies have different brittlenesses. Nejati and Ghazvinian (2014) studied the influence of rock brittleness on fatigue characteristics and found that in the crack damage stage, microcrack density increased with increasing rock brittleness while fatigue life decreased. Salt rock is a good gas storage medium with low porosity, high ductility, stable chemical properties, and strong selfhealing abilities. With this in mind, Roberts et al. (2015) studied the law of the cyclic loading creep and the conventional static loading of salt rock, and found that there was no significant difference in the creep characteristics of salt rock for different stress paths. Wang et al. (2021b) studied the creep characteristics of salt rock for five different long-term cycles and found that the damage process of salt rock could be divided into the attenuation, stability, and acceleration stages, and that the larger the stress amplitude was, the larger the cumulative irreversible deformation was.

However, the surrounding rock of an abandoned coal mine energy storage power station is usually dominated by coal, which is a soft rock and has different mechanical properties than hard rock (Zhao et al., 2021). Zhong et al. (2019) studied the crack development of coal samples containing saturated water for different cyclic frequencies, loading rates, and amplitudes, and they found that pore water destroyed the original cracks and lead to tensile damage. In terms of water permeability, Yang et al. (2018) studied the change of coal permeability for a cyclic loading stress path and found that with the increasing number of cycles, coal permeability declined irreversibly, which was caused by irreversible deformation. However, there are still few research studies on the damage and fracture development of coal during a cyclic load. In this research, acoustic emission monitoring is used to study the change of the fracture development damage of coal under this type of load. The surrounding rock of the UPSHs is in different stress environment, the research results of this paper will be beneficial to UPSHs to choose a reasonable working condition, effectively reduce the destruction of the chamber surrounding rock, reduce the operation cost of the pumped-storage power station.

\section{EXPERIMENTAL DESIGN AND SCHEME}

\section{Specimen Preparation}

The coal block gathered in the field is black and bright with parallel beddings, good bonding, and strong brittleness, as shown in Figure 1A. According to the requirements of the International Rock Mechanics Test Regulations, coal samples are cut perpendicular to the coal bedding to produce 20 samples containing horizontal bedding, with a size of $100 \mathrm{~mm} \times$ $100 \mathrm{~mm} \times 100 \mathrm{~mm}$, as shown in Figures 1B,C. Previous research results show that the rock strength and the elastic modulus decrease exponentially with the increase of the scale. When the cross-sectional area of the sample is larger than $50 \mathrm{~mm}$ $\times 50 \mathrm{~mm}$, the uniaxial compressive strength of the cylindrical rock samples with a slenderness ratio between 1 and 3 changes only slightly, regardless of whether the cross-section is round or square. Ultrasonic testing equipment is used to test the uniformity of the rock standard samples. After the test, the p-wave velocity of coal samples is mostly near $1370 \mathrm{~m} / \mathrm{s}$, and 22 usable coal samples are screened out. The samples with large deviations are removed according to the test results.

\section{Test Instrument}

In this uniaxial compression test, a CSS-44300 servo electronic testing machine purchased by the State Key Laboratory of Coal Resources and Safe Mining of the China University of Mining and Technology is used, as shown in Figure 2A. This testing machine can synchronously collect the loading time, axial load, and axial deformation of a test block. 


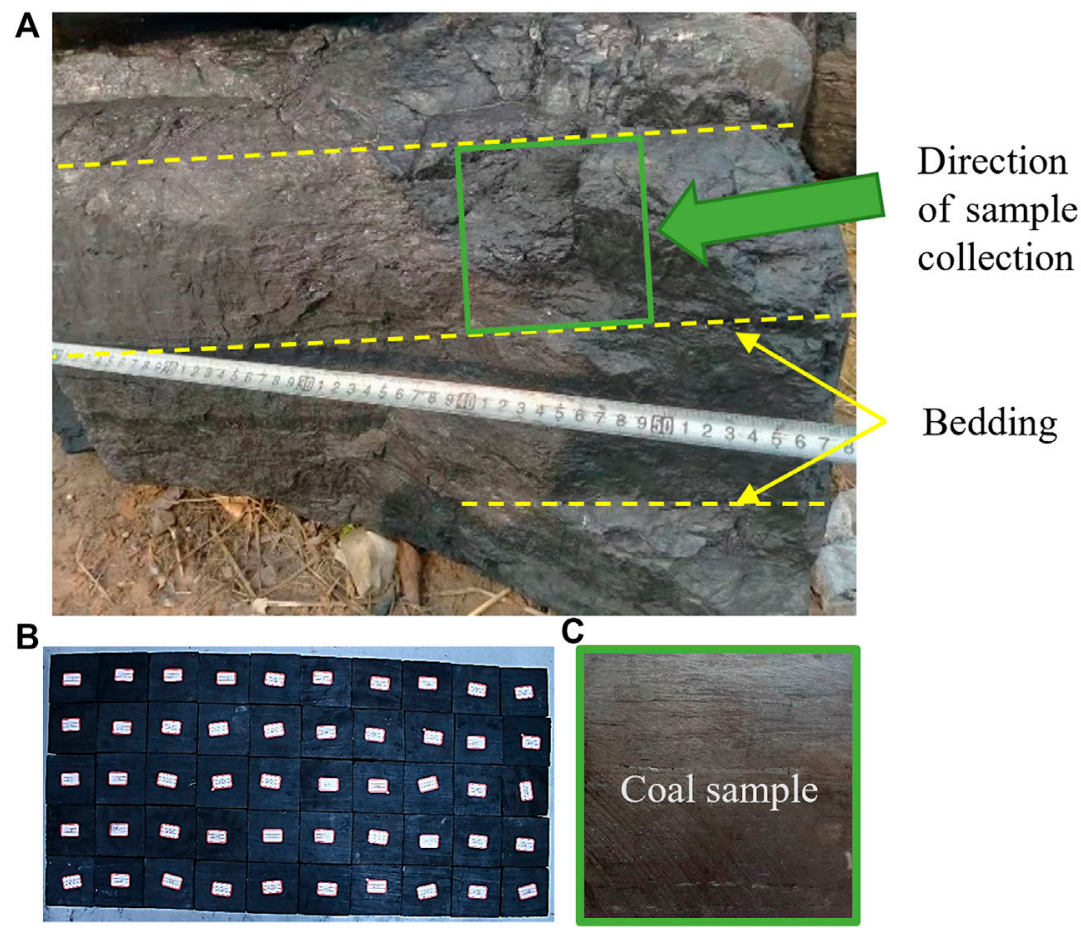

FIGURE 1 | Segments of the coal specimens (A) Field coal block and bedding distribution; (B) Finished product samples; (C) Single coal sample.

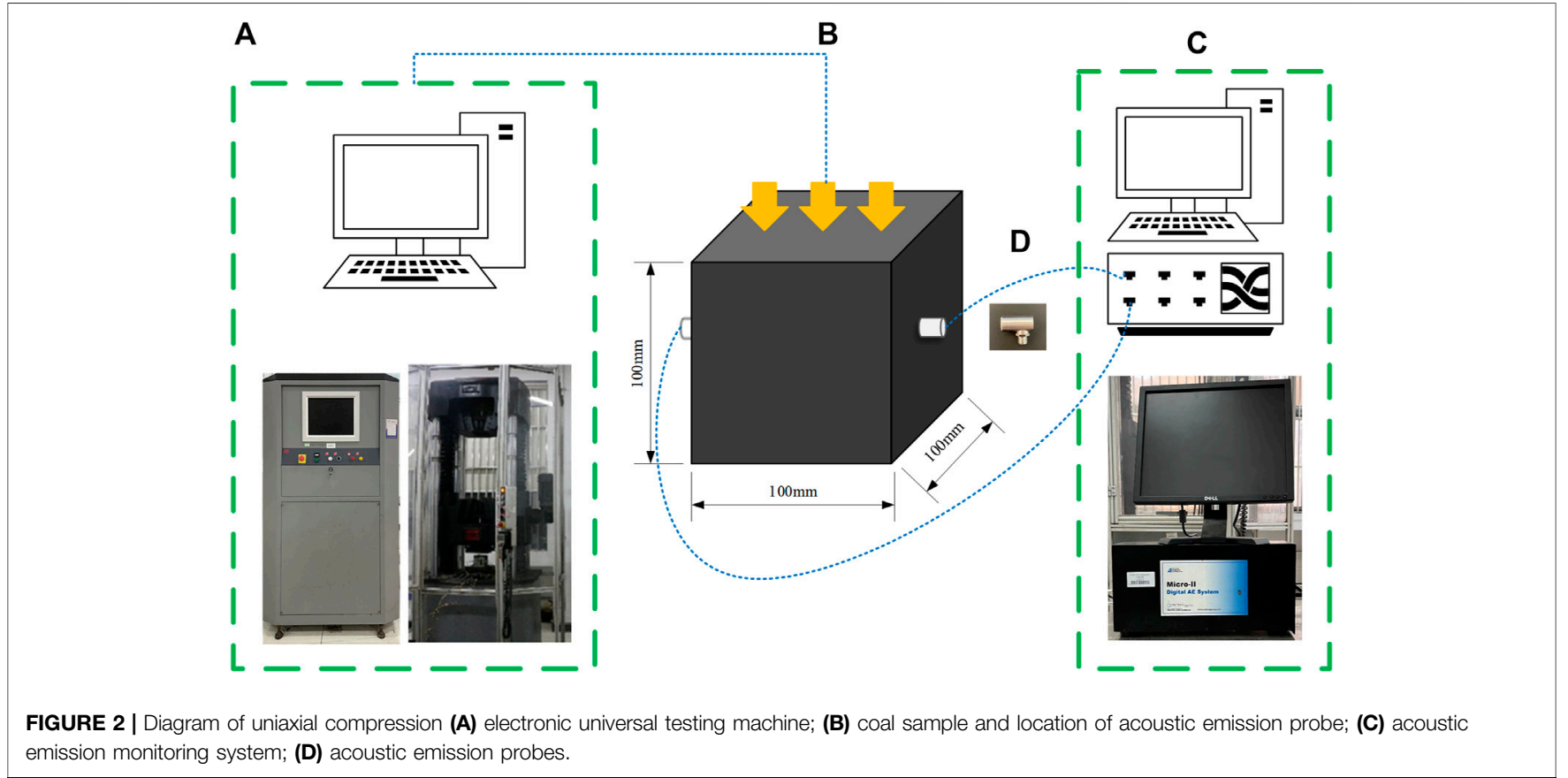

In this research, a PCI-2 acoustic emission monitoring system from the American Acoustical Company is used to record the acoustic emission activities of rock during the loading process. The system is composed of an acoustic emission host, preamplifier, and acoustic emission probe, as shown in
Figure 2C. The acoustic emission preamplifier can provide gains of $20 \mathrm{~dB}, 40 \mathrm{~dB}$, and $60 \mathrm{~dB}$ in three different gears. The type of acoustic emission probe used is Beijing Soft Lead RS-54A, with a diameter of $8 \mathrm{~mm}$ and a monitoring frequency range of $100-900 \mathrm{kHz}$, as shown in Figure 2D. In order to ensure the 

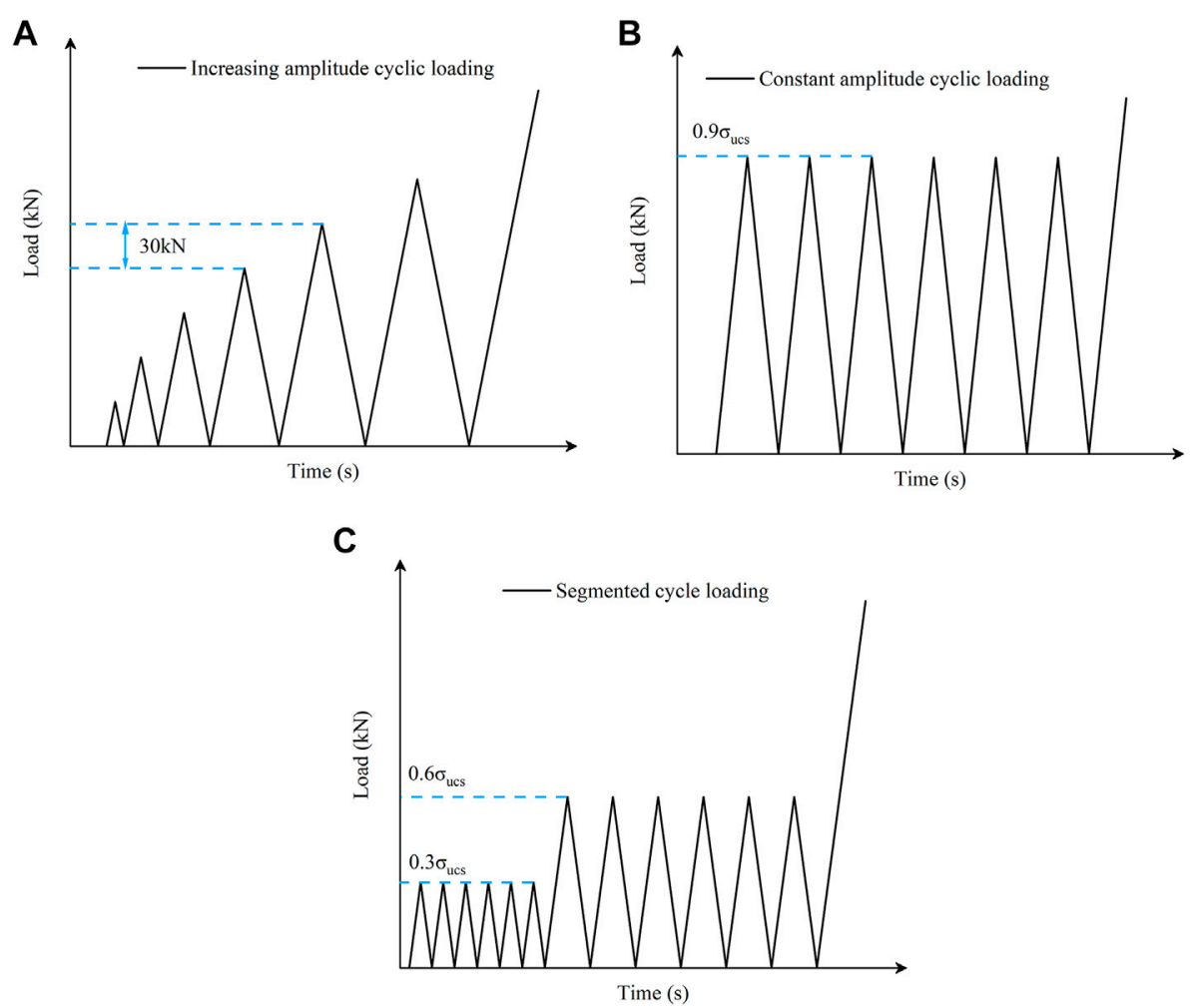

FIGURE 3 | Corresponding curves for load and time with different cyclic loading paths. (A) Waveforms with stepwise increasing amplitudes; (B) Waveforms with constant amplitudes; (C) Waveforms with multi-level cyclic amplitude.

accuracy of sampling in this research, acoustic emission probes are arranged according to the linear positioning method, and the lead breaking method is used to determine that the lead breaking amplitude monitored by the two probes exceeds $95 \mathrm{~dB}$, which meets the requirements of the acoustic emission monitoring test. In each test, the ambient sound is collected and analyzed, the preamplifier gain is set to $40 \mathrm{~dB}$, and the sampling frequency is set to $3 \mathrm{MHz}$.

\section{Test Scheme}

There are three different cyclic loading modes designed for the uniaxial compression test of coal samples, as shown in Figure 3, which are increasing cyclic loading amplitude, constant amplitude cyclic loading, and graded cyclic loading. Firstly, in order to determine the stress threshold of uniaxial cyclic loading, five rock samples are selected for the static uniaxial compression tests to obtain the uniaxial compressive strength and the Young's modulus of the coal samples. Then, the following three cyclic loading tests are conducted:

1) A uniaxial increment cyclic loading amplitude test is conducted. The load control loading method is adopted for loading. The loading rate is controlled at $0.05 \mathrm{MPa} / \mathrm{s}(0.5 \mathrm{kN} /$ $\mathrm{s})$, and the cyclic stress gradient is set to $3 \mathrm{MPa}(30 \mathrm{kN})$. At the end of six cycles, the specimen is compressed and destroyed.

2) A uniaxial constant amplitude cyclic loading test is conducted using the load control loading method for loading and unloading, and the loading and unloading rate is controlled at $0.05 \mathrm{MPa} / \mathrm{s}(0.5 \mathrm{kN} / \mathrm{s})$. The first load is $90 \%$ of the uniaxial strength of the sample, then the sample is unloaded to $0.5 \mathrm{MPa}$, and then the sample is cyclically loaded and unloaded six times in this interval. Finally, the sample is compressed and destroyed.

3) Cyclic loading tests are carried out in stages. The loading rate is controlled at $0.05 \mathrm{MPa} / \mathrm{s}(0.5 \mathrm{kN} / \mathrm{s})$. In the first stage, the loading is conducted at $0.05 \mathrm{MPa}$, and then the cyclic loading is carried out six times within the range of $0.05 \mathrm{MPa}-30 \%$ of the uniaxial strength. Then, in the second stage, the cyclic loading is carried out six times within the range of $0.05 \mathrm{MPa}-60 \%$ of the uniaxial strength. In the final stage, the sample is compressed and destroyed.

\section{ANALYSIS OF THE ACOUSTIC EMISSION CHARACTERISTICS OF THE COAL SAMPLES FOR CYCLIC LOADING AND UNLOADING}

\section{Test Results and Analysis of the Mechanical Properties of the Coal Samples}

The mechanical properties of the coal samples are shown in Table 1, and the stress-strain curve with uniaxial compression is shown in Figure 4. It can be seen from the figure that the 


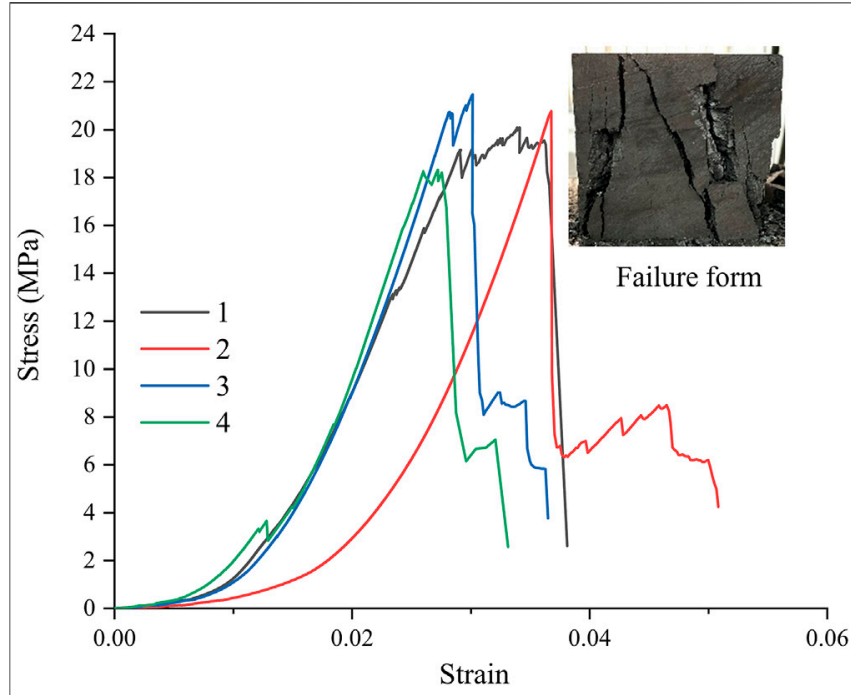

FIGURE 4 | Stress-strain curve in uniaxial compression.

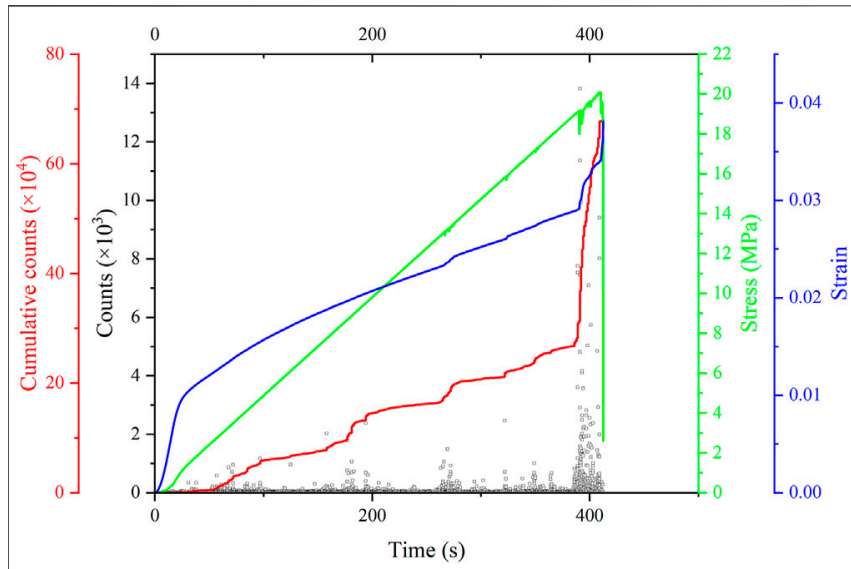

FIGURE 5 | The relationship between the sample stress, strain, acoustic emission count, and acoustic emission cumulative count with uniaxial compression.

TABLE 1 | Mechanical properties of coal

\begin{tabular}{lccc}
\hline Rock name & Density $\left(\mathbf{k g} / \mathbf{m}^{\mathbf{3}}\right)$ & Young's modulus (GPa) & $\begin{array}{c}\text { Uniaxial compressive strength } \\
\text { (MPa) }\end{array}$ \\
\hline Coal & $1,318.92$ & 1.28 & 20.78 \\
\hline
\end{tabular}

maximum uniaxial compressive strength of the coal sample is the same as the strain at failure, and the physical properties of the four blocks are consistent, so these properties can be used for subsequent tests. In the process of loading, the coal sample first appears to have a splitting crack. Then the sample is destroyed in the splitting and shear mixed fracture mode, and a large number of small splashes appear when the destruction occurs.

\section{Coupling Analysis of the Mechanical Properties and Acoustic Emission of Coal Samples During Cyclic Loading and Unloading}

The deformation and the failure of rocks are always accompanied by the release of strain energy in the form of elastic waves, which is called the acoustic emission phenomenon (Liu et al., 2020a; Liu et al., 2020b; Jiang et al., 2016). The AE of a rock mass with the action of loading stress can be divided into two categories. One category is the acoustic emission caused by severe elastic vibration due to the change of the elastic strain of the rock, and the other category is the acoustic emission caused by the sliding friction between microcracks (Chmel and Shcherbakov 2013).

Four coal samples are taken for each cyclic loading path. For better research, only representative test results are selected for analysis. In order to comprehensively observe and analyze the relationship between the stress on the coal samples and the acoustic emission, these data are placed on a graph. As shown in Figure 5, there are three curves and one group of scatter points in the figure, which represent the curves of the cumulative counts and the times of the stress, strain, and acoustic emission events of the sample. A scatter plot of the acoustic emission ring count rate and the time is created.

It can be seen from Figure 5 that the strain under uniaxial compression is divided into four stages: the compaction stage, the elastic deformation stage, the plastic deformation stage, and the post-peak stage. Additionally, during the loading process of sample 1-1, the acoustic emission process is divided into three stages. The first stage is the acoustic emission contingency stage in which only sporadic acoustic emission signals appear and the acoustic emission count rate and cumulative count values are very low because the sample is in the compaction stage, and there are basically no new cracks in the interior. The second stage is the $\mathrm{AE}$ development stage, in which the $\mathrm{AE}$ count rate increases gradually but still remains at a low level. The cumulative count of AE events increases gradually and presents a step shape, indicating that new cracks begin to appear inside the test and form cracks with the expansion and convergence of new cracks. The final stage is the peak stage of acoustic emission, and the peak stage occurs in a sample near destruction. For this stage, the acoustic emission event count rate increases by an order of magnitude, and the number of accumulated acoustic emission events dramatically increases. This is due to the fast expansion of cracks and broken blocks.

For uniaxial cyclic loading and unloading, the relationship between the acoustic emission ringing count rate, the cumulative count of the acoustic emission events, the loading stress, the 


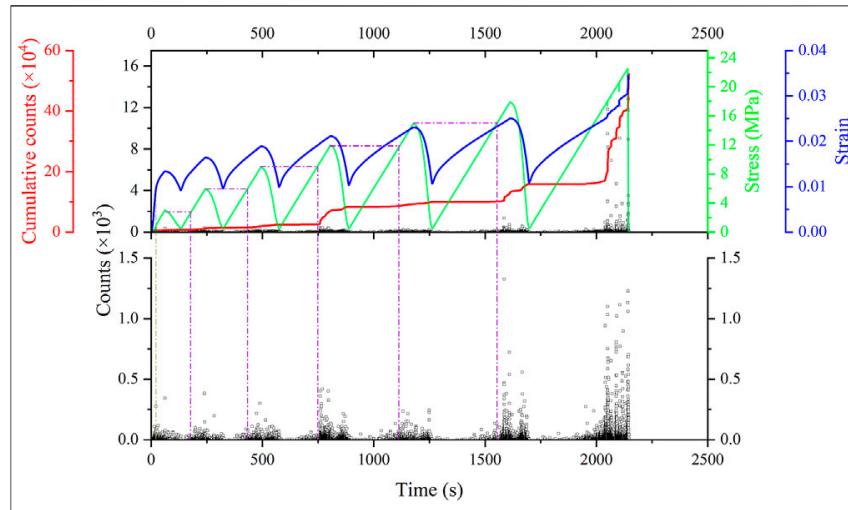

FIGURE 6 | Relationship between axial stress, axial strain, and acoustic emission for cyclic loading with a uniaxial increment.

sample strain, and the monitoring time of the rock specimens is shown in Figures 7-9. In order to facilitate analysis, the AE ring count rate in the figure is enlarged.

In the process of increasing cycle loading and unloading, an obvious Kaiser effect appears; that is, when the stress value reaches the peak value of the previous loading, the bearing rock presents an obvious acoustic emission phenomenon (the purple dotted line in Figure 6. When the stress value does not reach the peak value of the last loading stress, acoustic emission also occurs, which is called the Felicity phenomenon.

In each cycle, with the increasing load, the phenomenon of weak acoustic emission first appears, and then the acoustic emission frequency increases rapidly. When the stress value exceeds the maximum value of the last cycle, the acoustic emission time increases rapidly and reaches the maximum value at the stress peak of this cycle. At the unloading stage of each cycle, a large number of acoustic emission phenomena appear at the initial unloading stage and then disappear with the decrease of the stress value to a certain extent. However, as the stress value at the unloading point of each cycle continues to increase, the acoustic emission phenomenon becomes active again in the unloading process, and the load of this phenomenon is close to the peak value of the last cycle, which is the post-Kaiser phenomenon. The appearance of the Kaiser effect and the Felicity effect indicates that in a certain unloading process, the rock not only recovers its elastic deformation, but also changes its plastic deformation (Fan et al., 2020b; Kang et al., 2021).

With the process of cyclic loading and unloading, the maximum emission count rate of each cycle increases from 400 times to about 1,250 times before failure. The maximum emission rate in each cycle is greater than that in the previous cycle; specifically, at the moment before failure, the maximum emission count rate reaches 1,500 . This shows that with the increase of the number of cycles, the peak value of the cyclic load increases and the damage degree of the rock intensifies. As can be seen from the cumulative count curve, the cumulative AE count increases significantly by three times over a span of time, and it then reaches the maximum value near the failure of the sample. The significant increases corresponded to 9.5, 16.47, and
17.28 $\mathrm{MPa}$, respectively. This shows that these are the stages at which a large number of fissures are produced or at which the fissures are rapidly expanded and transfixed.

In the loading process of constant amplitude cyclic loading and unloading, as shown in Figure 7, the AE phenomenon appears periodically, and the cumulative amount of sound emission gradually increases, increasing especially rapidly in the first cyclic loading stage and the final failure stage. In each cyclic loading process, the $\mathrm{AE}$ counting rate value increases gradually and reaches the extreme value at the loading stress maximum. The maximum $\mathrm{AE}$ counting rate in the first cycle is 94 times, and the maximum AE counting rate in the following cycles is between 50 and 70 times. At each cycle unloading stage, the $\mathrm{AE}$ activity weakens rapidly, and when the stress reaches the lowest point, the $\mathrm{AE}$ phenomenon basically disappears. In the constant amplitude loading and unloading cycle, the maximum stress value is close to the uniaxial compressive strength of rock, so an obvious acoustic emission phenomenon appears in each cycle, the maximum emission count rate fluctuates within a certain range, and the acoustic emission activity does not decline significantly. It can be seen that for the loading close to the maximum uniaxial compressive strength of the sample, new cracks are constantly generated and developed inside the coal sample. The coal sample is in a state of continuous damage, and each time the coal sample is in the active stage of acoustic emission, this indicates that the coal sample is about to experience yield failure.

For the condition of piecewise cyclic loading and unloading, as shown in Figure 8, the AE phenomenon appears periodically, and the cumulative number of the $\mathrm{AE}$ increases gradually, and increases especially rapidly for the increasing amplitude and the final failure stage. In the process of cyclic loading and unloading in the first stage, the maximum $\mathrm{AE}$ count rate in each cycle reaches the maximum of 208 times in the first cycle, 66 times and 74 times in the following two cycles, and then stabilizes within the range of 21-34 times, presenting a trend of fluctuation and overall decline. With the process of cyclic loading and unloading, the AE activity of the coal samples decreases gradually. In the process of cyclic loading and unloading in the second stage, the maximum $\mathrm{AE}$ count rate reaches a maximum value of 234 times in the first cycle and then fluctuates. Although the trend of the acoustic emission count rate of the coal samples is similar to that in the first stage, the acoustic emission activity in each cycle is

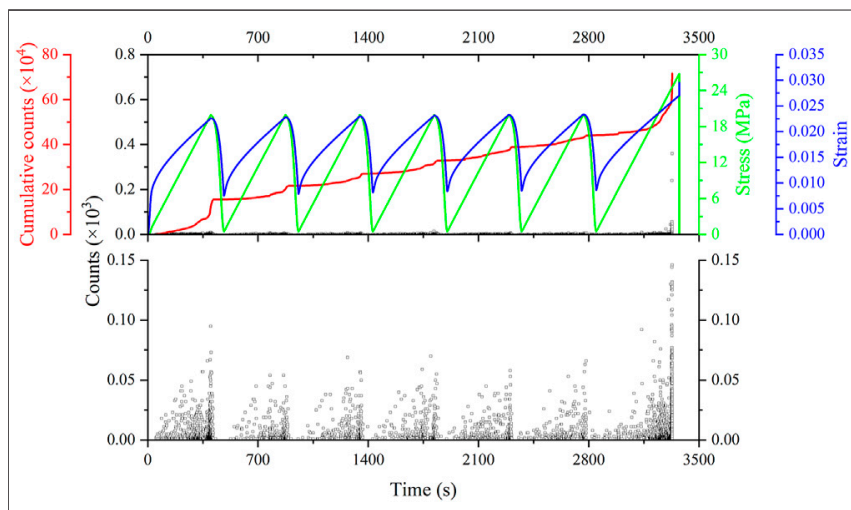

FIGURE 7 | The relationship between the axial stress, axial strain, acoustic emission, and uniaxial constant amplitude cyclic loading. 


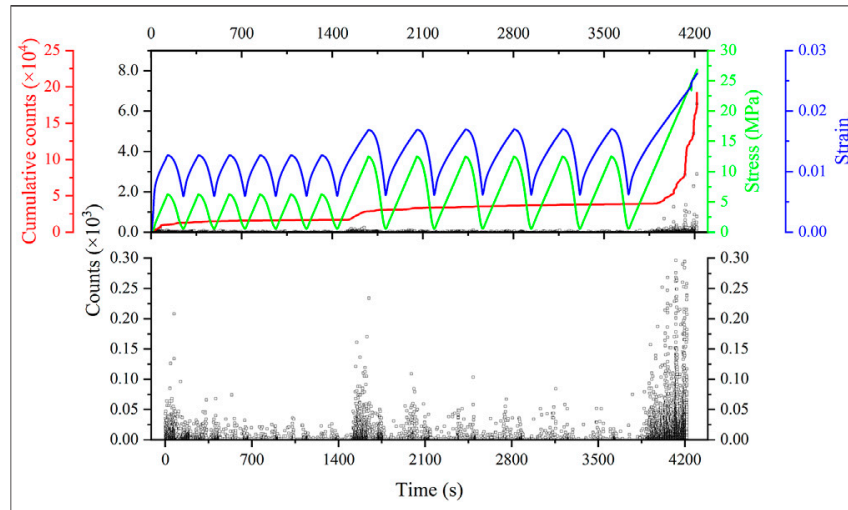

FIGURE 8 | The relationship between the axial stress, axial strain, acoustic emission, and uniaxial segmented cyclic loading and unloading.

higher than that in the first stage. This indicates that the upper limit of the load has a significant impact on the acoustic emission of the coal samples. The greater the load is, the more active the acoustic emission is. When the load in the second stage exceeds that in the first stage, the $\mathrm{AE}$ events increase rapidly, indicating that the Kaiser effect of the acoustic emission activity of the coal samples is an inherent attribute of the coal samples. The AE activity increases sharply when the coal sample is near failure, and then decreases sharply and disappears after failure.

To summarize, whether in uniaxial loading or in each cycle of loading and unloading, the acoustic emission phenomenon of the coal samples exists in three stages: the calm stage, the increasing stage, and the active stage. In different types of cyclic loading and unloading, the cumulative value of the $\mathrm{AE}$ keeps increasing until the sample is destroyed, and the AE events are mainly caused by the propagation of cracks, indicating that new cracks are constantly generated and developed inside the coal sample, and the damage degree of the coal sample keeps deepening. In different unloading stages of the cycle, acoustic emission phenomena also occur, indicating that the coal samples also have damage changes in the unloading process, but the degree is relatively small. Compared with cyclic loading and unloading at a low stress level, the high stress cycle close to uniaxial compressive strength continuously promotes the formation and development of cracks in the coal samples, so the acoustic emission is always in an active stage.

\section{ANALYSIS OF ENERGY AND DAMAGE VARIATION OF COAL SAMPLES FOR DIFFERENT CYCLIC LOADING AND UNLOADING STRESS PATHS}

\section{Evolution Law of Coal Sample Energy for Different Cyclic Loading and Unloading Paths}

With regards to energy, during the process of rock deformation and failure, the rock always exchanges energy with the outside world. Part of the energy absorbed by rock is used for the internal damage and plastic deformation of rock, namely the dissipated energy, while the other part of the energy is stored in the form of elastic energy and released in the process of external load reduction. Thus, the energy transferred to the rock sample can be regarded as the sum of the elastic energy and the dissipated energy:

$$
U=U^{e}+U^{d}
$$

where $U$ is the energy stored by the test loaded sample, $U^{e}$ is the elastic energy stored in the sample during test loading, and $U^{d}$ is the energy dissipated by the sample during the test loading process. These terms can be obtained with the following formula:

$$
\begin{aligned}
U & =\int_{0}^{V} u d v \\
U^{e} & =\int_{0}^{V} u^{e} d v
\end{aligned}
$$

where $u$ is the energy storage density, which is represented by the area surrounded by the loading curve and the strain axis, $u^{e}$ is the elastic energy density, which is represented by the area surrounded by the unloading curve and the strain axis, and $u^{d}$ is the area surrounded by the loading curve, the unloading curve, and the strain axis, as shown in Figure 9.

$$
\begin{gathered}
u=\int_{0}^{\varepsilon_{2}} \sigma d \varepsilon \\
u^{e}=\int_{\varepsilon_{1}}^{\varepsilon_{2}} \sigma d \varepsilon \\
u^{d}=\int_{0}^{\varepsilon_{2}} \sigma d \varepsilon-\int_{\varepsilon_{1}}^{\varepsilon_{2}} \sigma d \varepsilon
\end{gathered}
$$

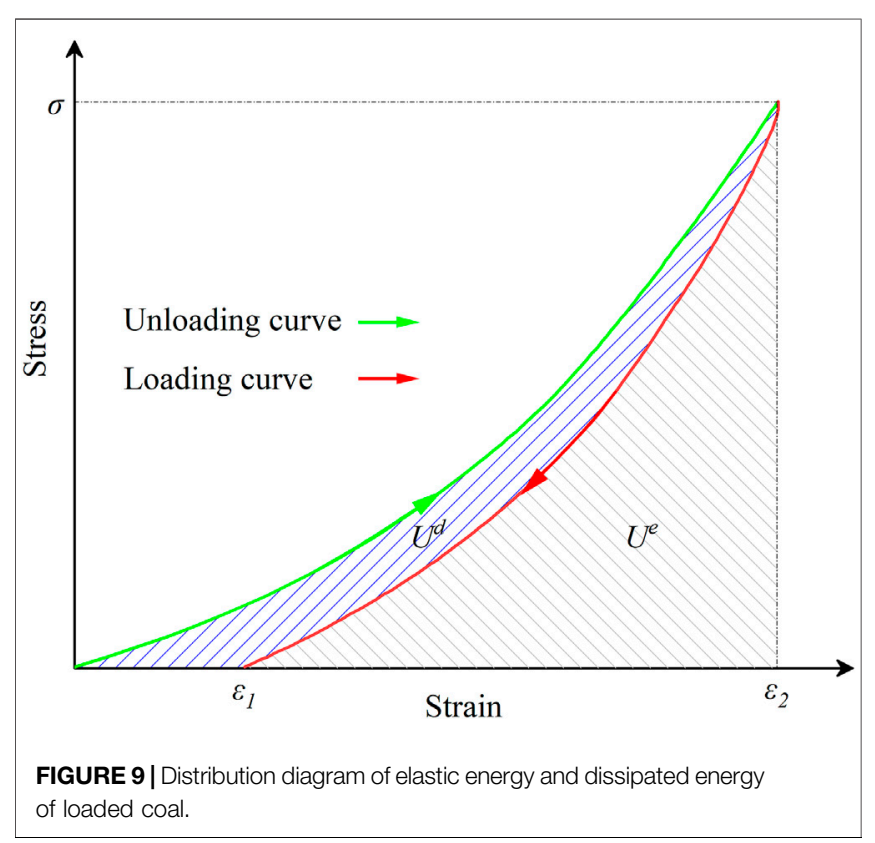


TABLE 2 | Calculation results for each cycle energy for different loading modes.

\begin{tabular}{|c|c|c|c|c|c|c|c|c|c|}
\hline \multirow{2}{*}{$\begin{array}{l}\text { Load } \\
\text { model }\end{array}$} & \multicolumn{3}{|c|}{ Amplification cycle loading } & \multicolumn{3}{|c|}{ Constant amplitude cycle loading } & \multicolumn{3}{|c|}{ Section cycle loading } \\
\hline & $\begin{array}{c}\text { Total } \\
\text { energy } \\
\text { kJ }\end{array}$ & $\begin{array}{c}\text { Elastic } \\
\text { energy } \\
\text { KJ }\end{array}$ & $\begin{array}{c}\text { Dissipated } \\
\text { energy } \\
\text { kJ }\end{array}$ & $\begin{array}{c}\text { Total } \\
\text { energy } \\
\text { kJ }\end{array}$ & $\begin{array}{c}\text { Elastic } \\
\text { energy } \\
\mathbf{k J}\end{array}$ & $\begin{array}{c}\text { Dissipated } \\
\text { energy } \\
\text { kJ }\end{array}$ & $\begin{array}{c}\text { Total } \\
\text { energy } \\
\text { kJ }\end{array}$ & $\begin{array}{c}\text { Elastic } \\
\text { energy } \\
\text { kJ }\end{array}$ & $\begin{array}{c}\text { Dissipated } \\
\text { energy } \\
\text { kJ }\end{array}$ \\
\hline 1 & 5.56 & 4.33 & 1.23 & 121.12 & 104.09 & 17.03 & 16.49 & 13.59 & 2.9 \\
\hline 2 & 17.94 & 14.78 & 3.16 & 114.78 & 104.46 & 10.32 & 14.96 & 13.52 & 1.44 \\
\hline 3 & 32.66 & 28.89 & 3.77 & 113.81 & 104.54 & 9.27 & 14.89 & 13.59 & 1.3 \\
\hline 4 & 51.89 & 46.06 & 5.83 & 113.3 & 104.52 & 8.78 & 14.81 & 13.53 & 1.28 \\
\hline 5 & 75.21 & 67.93 & 7.28 & 115.54 & 105.51 & 10.03 & 14.8 & 13.56 & 1.24 \\
\hline 6 & 110.81 & 101.05 & 9.76 & 113.87 & 105.51 & 8.36 & 14.72 & 13.5 & 1.22 \\
\hline 7 & & & & & & & 50.01 & 46.45 & 3.56 \\
\hline 8 & & & & & & & 50.76 & 46.64 & 4.12 \\
\hline 9 & & & & & & & 50.57 & 46.59 & 3.98 \\
\hline 10 & & & & & & & 50.54 & 46.64 & 3.9 \\
\hline 11 & & & & & & & 50.46 & 46.59 & 3.87 \\
\hline 12 & & & & & & & 50.34 & 46.64 & 3.7 \\
\hline
\end{tabular}

A

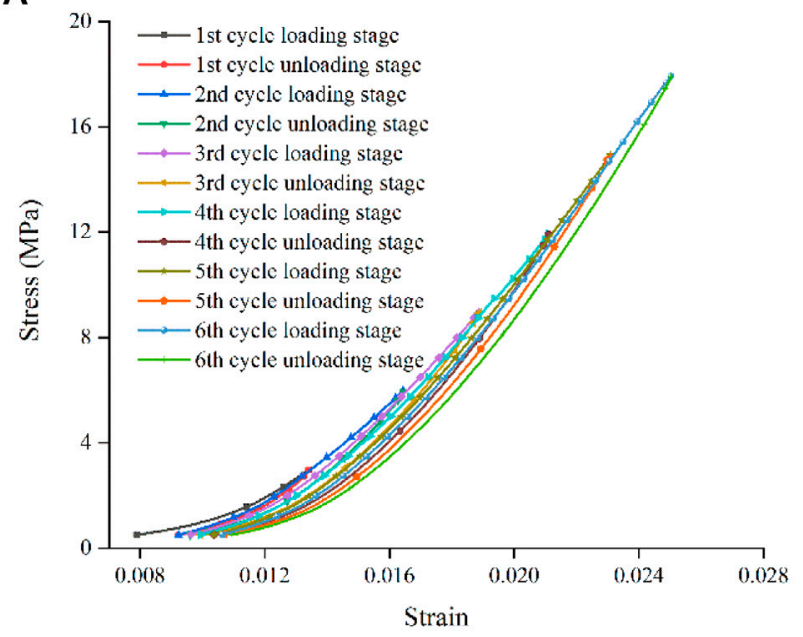

C

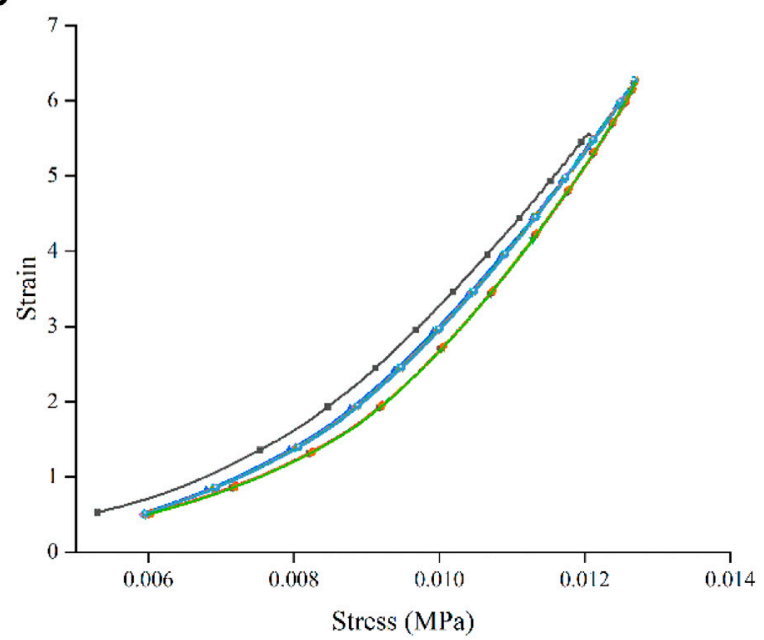

B

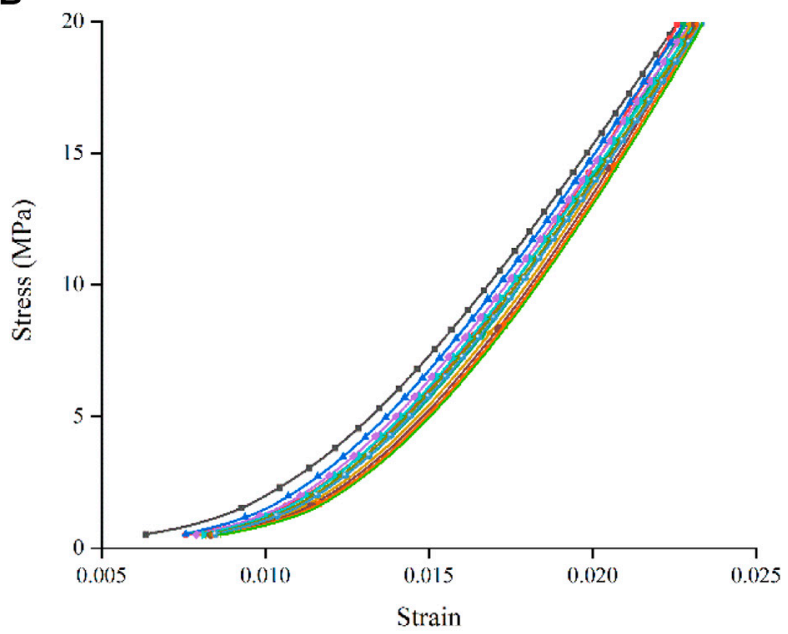

D

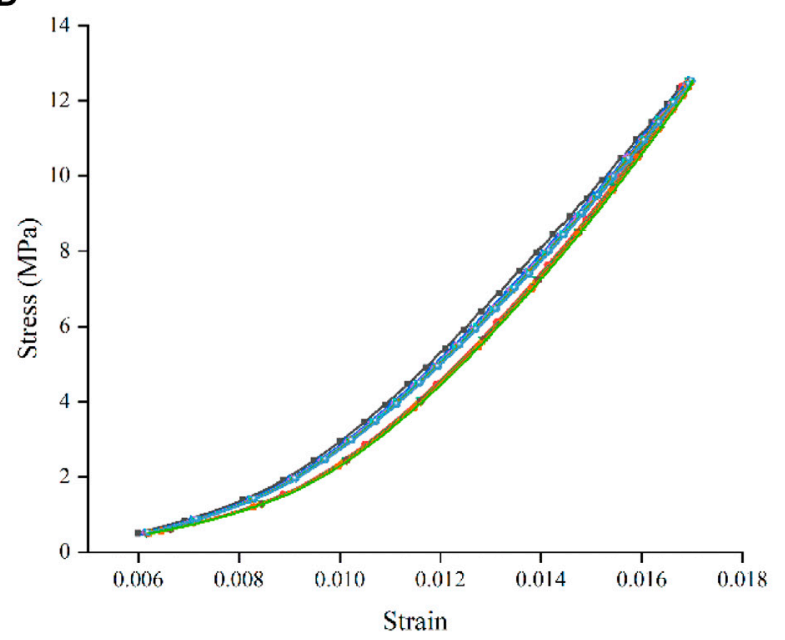

FIGURE 10 | Stress-strain curves of coal samples for different cyclic loading and unloading paths. (A) Increased amplitude cycle loading; (B) Constant amplitude cyclic loading; (C) The first stage of loading in sections; (D) The second stage of loading in section. 
A

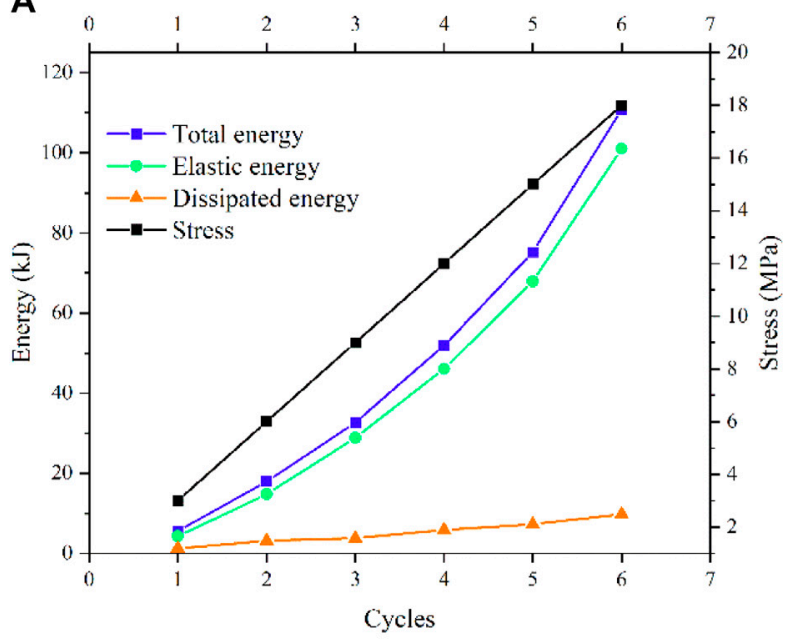

B
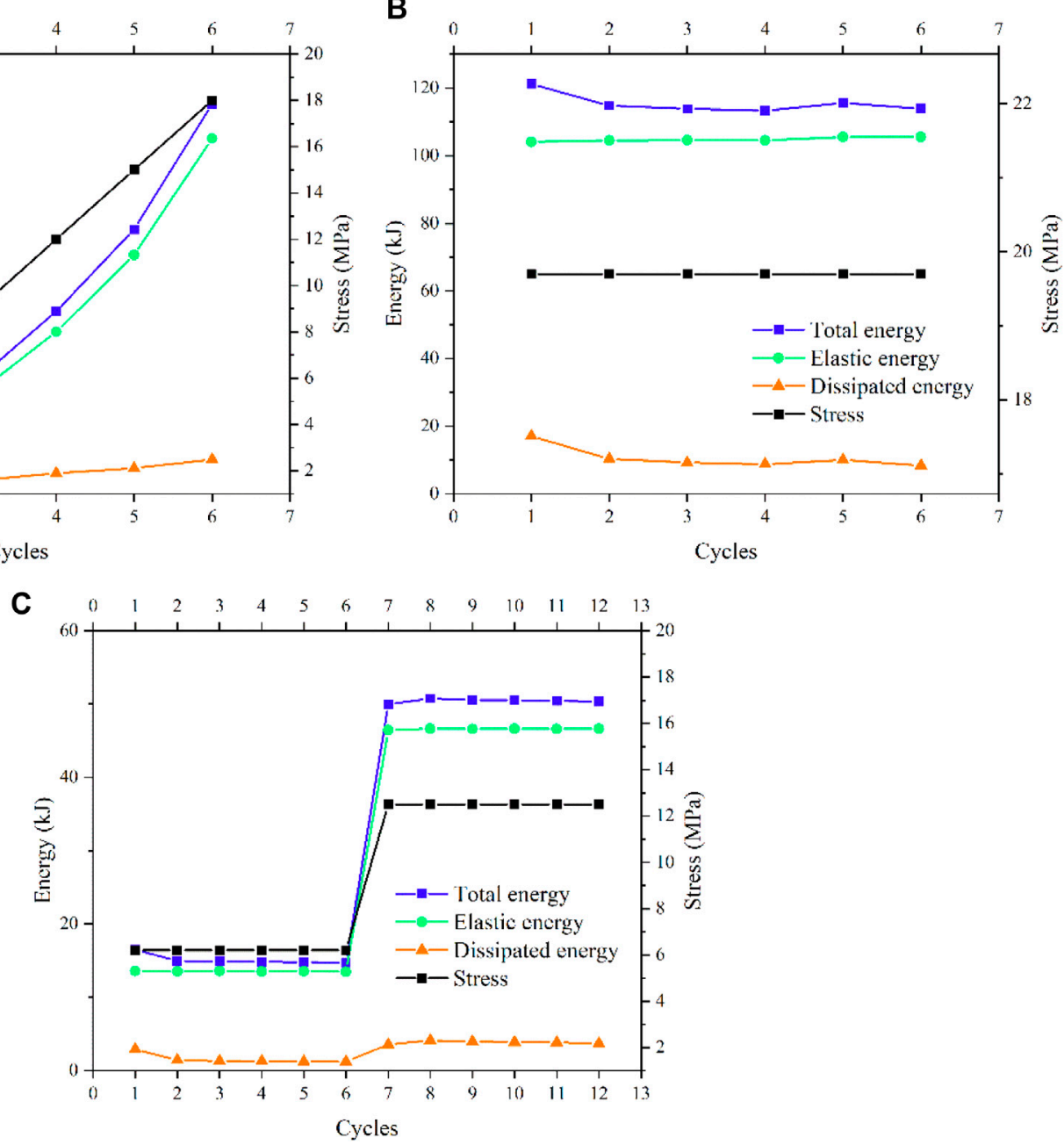

FIGURE 11 | Energy evolution diagram of each cycle for different loading modes. (A) Increased amplitude cycle loading; (B) Constant amplitude cyclic loading; (C) Section cycle loading.

In summary, the elastic energy density and the dissipated energy density of the loaded rock mass can be obtained by calculating the area indicated in Figure 9.

According to the above calculation method for the dissipated energy density, the stress-strain curves of the coal samples for different cyclic loading and unloading modes are integrated to obtain the total energy, elastic energy, and dissipated energy corresponding to each stress cycle, as shown in Table 2 and Figures 10, 11.

For the three cyclic loading and unloading stress paths, the elastic energy accounts for most of the total energy absorbed by the rock, indicating that the energy transferred to the coal sample is mainly stored in the form of elastic energy before rock failure. The energy evolution of the coal sample is related to the external load value and the number of cycles, which is most affected by the external load value. For the same load level, the elastic energy of the coal sample remains the same, but the dissipation energy undergoes variation. For the cyclic increase condition, the total energy, elastic energy, and dissipated energy show nonlinear increasing trends, and the proportion of dissipated energy becomes larger, indicating that the upper limit of the load increases, the cracks in the sample continue to expand, and damage development accelerates. During constant amplitude cyclic loading and unloading, the elastic energy shows an overall increasing trend, indicating that with the increasing number of cycles, the inner rock gradually hardens. The dissipated energy decreases gradually, then suddenly decreases after the first cycle, and then decreases after the second cycle, indicating that the primary pores, cracks, and secondary cracks of the sample close during cyclic loading. The energy of each section is similar to that of the constant amplitude. When the loading process enters a new stage, the energy increases rapidly, which confirms that new damage occurs in the coal sample for the new load level.

As can be seen from Figure 12, regardless of the loading mode, the dissipated energy ratio reaches the maximum value between 0.14 and 0.22 in the first cycle, then decreases slowly in the subsequent cycle, and tends to be stable between 0.07 and 0.09 . 
A

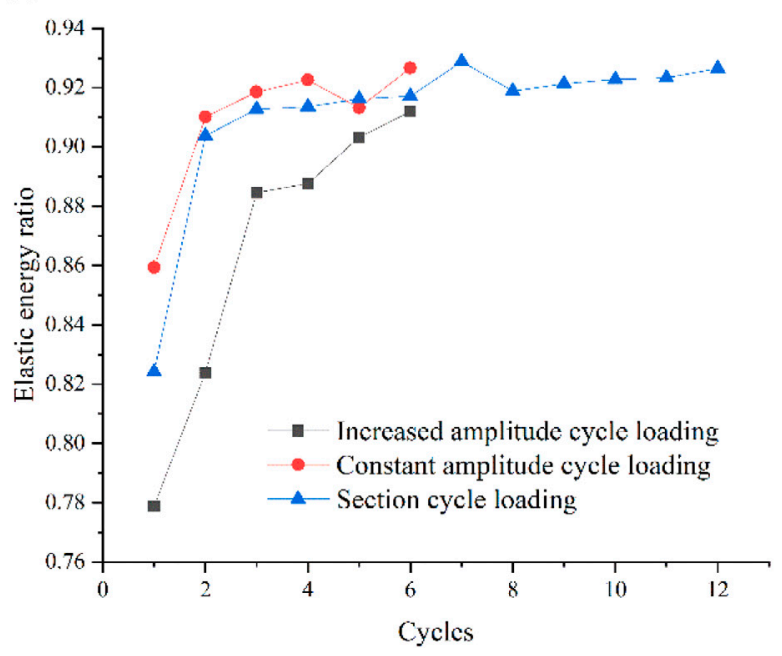

B

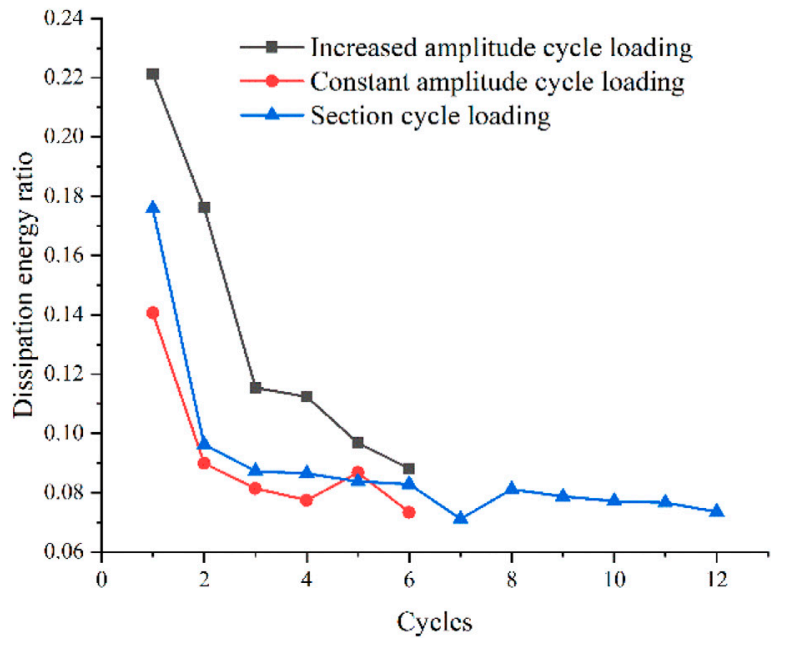

FIGURE 12 | Changes in the proportion of elastic energy and dissipated energy with the number of cycles for different stress paths. (A) Change of the elastic energy ratio with the number of cycles; $(\mathbf{B})$ The proportion of dissipated energy changes with the number of cycles.

This shows that in the first cycle, the energy is due to the original crack closure and the friction effect of consumption. In the subsequent cycle, the elastic energy stored in the coal sample increases continuously, and the elastic property will be released immediately after the coal sample is damaged; this is why the coal sample damaged piece splash phenomenon occurs. During the cyclic loading and unloading at constant amplitude, the dissipated energy fluctuates, which is because the upper limit of the stress is close to the uniaxial failure strength of the coal samples, and cracks are connected in the coal body during cyclic loading. In the piecewise loading process, the proportion of elastic energy increases with the increase of the upper limit of stress, which is similar to the change of the proportion of dissipated energy in the increasing cycle of loading and unloading, indicating that when the external load increases, the energy is always stored as elastic energy first. Since the upper limit of the stress is stable, the decreasing trend of the second stage is similar to that of constant amplitude cyclic loading and unloading and the dissipated energy proportion increases, indicating that there is a phenomenon of unstable development of cracks in the loading process of the coal samples.

\section{Coal Sample Damage Evolution Law for Different Cyclic Loading and Unloading Paths}

In solid materials, damage refers to the existence and development of internal cracks. In the material, these defects are discontinuous, but at larger sizes, they are considered continuous. There are many ways to define damage variables. One method involves variables based on continuum damage theory (CDT), such as the residual axial

TABLE 3 | Calculation of damage variables of coal samples for different cyclic loading paths.

\begin{tabular}{|c|c|c|c|c|c|c|}
\hline \multirow{2}{*}{$\begin{array}{l}\text { Load } \\
\text { model }\end{array}$} & \multicolumn{2}{|c|}{ Amplification cycle loading } & \multicolumn{2}{|c|}{ Constant amplitude cycle loading } & \multicolumn{2}{|c|}{ Section cycle loading } \\
\hline & $\begin{array}{c}\text { Total dissipated } \\
\text { energy }(k J)\end{array}$ & $\begin{array}{c}\text { Damage } \\
\text { variable D }\end{array}$ & $\begin{array}{c}\text { Total dissipated } \\
\text { energy }(k J)\end{array}$ & $\begin{array}{c}\text { Damage } \\
\text { variable D }\end{array}$ & $\begin{array}{c}\text { Total dissipated } \\
\text { energy }(k J)\end{array}$ & $\begin{array}{c}\text { Damage } \\
\text { variable D }\end{array}$ \\
\hline 1 & 1.23 & 0.01 & 17.03 & 0.14 & 2.9 & 0.04 \\
\hline 2 & 4.39 & 0.03 & 27.35 & 0.21 & 4.34 & 0.05 \\
\hline 3 & 8.16 & 0.06 & 36.62 & 0.26 & 5.64 & 0.07 \\
\hline 4 & 13.99 & 0.11 & 45.4 & 0.30 & 6.92 & 0.09 \\
\hline 5 & 21.27 & 0.16 & 55.43 & 0.34 & 8.16 & 0.10 \\
\hline 6 & 31.03 & 0.24 & 63.79 & 0.38 & 9.38 & 0.12 \\
\hline 7 & & & & & 12.94 & 0.16 \\
\hline 8 & & & & & 17.06 & 0.22 \\
\hline 9 & & & & & 21.04 & 0.27 \\
\hline 10 & & & & & 24.94 & 0.32 \\
\hline 11 & & & & & 28.81 & 0.36 \\
\hline 12 & & & & & 32.51 & 0.41 \\
\hline
\end{tabular}




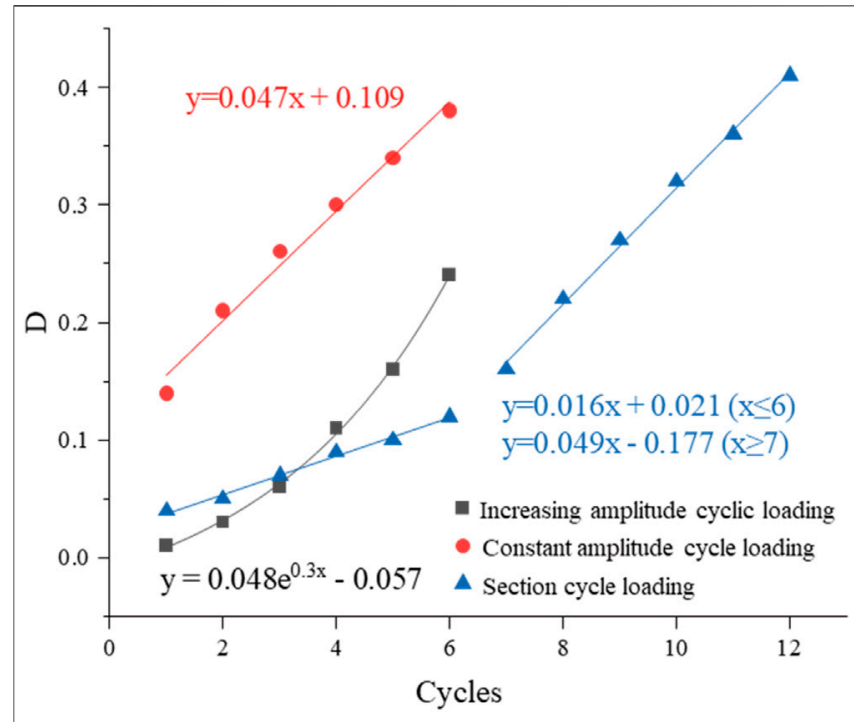

FIGURE 13 | The relationship between the damage and cycle loading and unloading times.

strain, residual volume strain, and elastic modulus. Another method involves variables based on energy methods, such as dissipated energy, acoustic emission, and ultrasonic speed. Regardless of the parameters used, the damage evolution must be consistent with microcrack initiation, stability, and unstable propagation (Xiao et al., 2010). A large number of researchers have applied the dissipative structure theory to the field of rock mechanics. They believe that the damage and failure process of rock is an irreversible process of energy dissipation, and the change of rock mechanical properties can be accurately reflected by defining specific damage variables. In this research, the ratio of the accumulated dissipated energy of a certain cycle to the accumulated total strain energy is defined as the damage variable of this cycle, and the total strain energy is the sum of the subelastic strain energy and the accumulated dissipated energy, as shown in Formula (8). Then, the coal sample damage variable for each cycle is calculated as follows:

$$
\begin{gathered}
D_{i}=\frac{U_{i}^{d}}{U^{d}} \\
U^{d}=\sum_{i=1}^{j} U_{i}^{d}+U_{j}^{e}
\end{gathered}
$$

where $i$ is the $i$ th cycle, $j$ is the total number of cycles, $D_{i}$ is the damage change of the $i$ th cycle, $U_{i}^{d}$ is the accumulated dissipated energy of the $i$ th cycle, $U_{j}^{e}$ is the elastic energy of the $j$ th cycle, and $U^{d}$ is the total dissipated energy after the rock is destroyed.

It can be seen from the above formula that when the sample is not loaded or in a fully elastic strain state, the dissipated energy $U_{0}^{d}$ of the sample is 0 , and the damage of the sample is 0 . When the coal sample is damaged during the loading process, the dissipated energy $U_{i}^{d}>0$ and the damage is irreversible. Then, the damage variable $\mathrm{D}$ is defined as:

$$
D=\sum_{i=1}^{i} D_{i} / U^{d}=\sum_{i=1}^{i} U_{i}^{d} /\left(\sum_{i=1}^{j} U_{i}^{d}++U_{j}^{e}\right)
$$

According to Formula Eq. 9, when the rock is completely destroyed, $i=j, D=1$, and there is an important loading and unloading process. The range of $\mathrm{D}$ is between 0 and 1 , which conforms to the defined rules of the damage variables. According to this rule, the damage variable values of the coal samples for various cyclic loading conditions are shown in Table 3.

It can be seen from Table 3 that for different cyclic loading and unloading paths, the damage degree is positively correlated with the loading and unloading times and the load size; that is, the damage degree of the samples increases with the increase of the cycle times and the load, which conforms to the basic characteristics of rock mechanics. Before loading, the damage degree for all samples is 0 , and after loading, the damage variable is about 0.4. In addition, according to previous research experience, when the damage degree of the rock sample exceeds 0.5, the sample is easily destroyed in the subsequent loading process, indicating that it is difficult to prepare coal and rock samples with damage degrees exceeding 0.5 . Figure 13 shows that the loading curve and the unloading curve of the coal sample coincide with the constant amplitude cycle of $0.3 \sigma_{u c s}$. It can be seen from the figure that the sample damage changes slowly in the process of constant amplitude loading with a small upper limit of the load. With an increase in the load, the damage of the sample increases nonlinearly; that is, the rate of damage increases continuously. However, for a constant amplitude load, the damage to the sample increases linearly within six cycles, and the rate of increase is stable between 0.04 and 0.05 .

\section{CONCLUSION}

In this research, the acoustic emission and energy evolution characteristics of coal samples are studied for different cyclic loading and unloading conditions. The damage variables of coal samples are defined with the energy method, and the damage evolution characteristics of coal are studied. The main conclusions are as follows:

1) For different stress paths, the AE law of the sample is highly correlated with the size of the external load. The closer the load is to the compressive strength of the coal sample, the more active the $\mathrm{AE}$ is, and cracks are constantly generated and expanded. For the low load cycle, the activity of the AE phenomenon decreases with the increase of the number of cycles, but for the cycle close to the compressive strength of the coal sample, the AE phenomenon is always active. The Felicity phenomenon appears in the acoustic emission of the coal samples, and the Kaiser effect appears in the unloading 
process, indicating that part of the plastic deformation is restored in the increasing cyclic unloading stage.

2) For the different types of cyclic loading and unloading described in Section 3, the disturbance of the increasing cyclic mode for the coal sample is the most obvious. With this stress path, the total absorbed energy, elastic strain energy, and dissipated energy of the coal increase nonlinearly, and the more elastic strain energy is stored, the more fragments are produced by coal sample failure. The elastic energy changes only slightly with the subsection loading and constant amplitude loading.

3) The damage degree of the coal sample increases with the increasing number of cycles. The smaller the load is, the smaller the damage degree is with the increasing number of cycles. The increase of the cyclic loading and unloading has the greatest influence on the damage to the coal, and the damage degree increases exponentially, which is not conducive to the stability of the coal samples. This shows that the design of a UPSH with an appropriate water level can benefit the stability of the surrounding rock of the chamber.

\section{REFERENCES}

Bilgili, M., Ozbek, A., Sahin, B., and Kahraman, A. (2015). An Overview of Renewable Electric Power Capacity and Progress in New Technologies in the World. Renew. Sust. Energ. Rev. 49, 323-334. doi:10.1016/j.rser.2015.04.148

Chmel, A., and Shcherbakov, I. (2013). A Comparative Acoustic Emission Study of Compression and Impact Fracture in Granite. Int. J. Rock Mech. Mining Sci. 64, 56-59. doi:10.1016/j.ijrmms.2013.08.025

Fan, J., Jiang, D., Liu, W., Wu, F., Chen, J., and Daemen, J. (2019). Discontinuous Fatigue of Salt Rock with Low-Stress Intervals. Int. J. Rock Mech. Mining Sci. 115, 77-86. doi:10.1016/j.ijrmms.2019.01.013

Fan, J. Y., Xie, H. P., Jie, C., Jiang, D., Li, C., Ngaha Tiedeu, W., et al. (2020a). Preliminary Feasibility Analysis of a Hybrid Pumped-Hydro Energy Storage System Using Abandoned Coal Mine Goafs. Appl. Energ. 258, 114007. doi:10. 1016/j.apenergy.2019.114007

Fan, J., Liu, W., Jiang, D., Chen, J., Tiedeu, W. N., and Daemen, J. J. K. (2020b). Time Interval Effect in Triaxial Discontinuous Cyclic Compression Tests and Simulations for the Residual Stress in Rock Salt. Rock Mech. Rock Eng. 53, 4061-4076. doi:10.1007/s00603-020-02150-y

$\mathrm{Fu}, \mathrm{B}, \mathrm{Hu}, \mathrm{L} . \mathrm{H}$, and Tang, C. A. (2020). Experimental and Numerical Investigations on Crack Development and Mechanical Behavior of marble under Uniaxial Cyclic Loading Compression. Int. J. Rock Mech. Mining Sci. 130, 104289. doi:10.1016/j.ijrmms.2020.104289

Gaudard, L., and Madani, K. (2019). Energy Storage Race: Has the Monopoly of Pumped-Storage in Europe Come to an End? Energy Policy 126, 22-29. doi:10. 1016/j.enpol.2018.11.003

Heap, M. J., Vinciguerra, S., and Meredith, P. G. (2009). The Evolution of Elastic Moduli with Increasing Crack Damage during Cyclic Stressing of a basalt from Mt. Etna Volcano. Tectonophysics 471, 153-160. doi:10.1016/j.tecto.2008. 10.004

Jia, C., Xu, W., Wang, R., Wang, W., Zhang, J., and Yu, J. (2018). Characterization of the Deformation Behavior of fine-grained sandstone by Triaxial Cyclic Loading. Construction Building Mater. 162, 113-123. doi:10.1016/j. conbuildmat.2017.12.001

Jiang, D., Fan, J., Chen, J., Li, L., and Cui, Y. (2016). A Mechanism of Fatigue in Salt under Discontinuous Cycle Loading. Int. J. Rock Mech. Mining Sci. 86, 255-260. doi:10.1016/j.ijrmms.2016.05.004

Kang, Y., Fan, J., Jiang, D., and Li, Z. (2021). Influence of Geological and Environmental Factors on the Reconsolidation Behavior of fine Granular Salt. Nat. Resour. Res. 30, 805-826. doi:10.1007/s11053-020-09732-1

\section{DATA AVAILABILITY STATEMENT}

The original contributions presented in the study are included in the article, further inquiries can be directed to the corresponding author.

\section{AUTHOR CONTRIBUTIONS}

Conceptualization, SZ; Data curation, SZ; Formal analysis, SZ; Investigation, SZ; Project administration, JS; Resources, XW; Software, TQ; Supervision, JS; Visualization, JS and TQ; Writing-original draft, SZ; Writing-review \& editing, SZ.

\section{FUNDING}

This research was funded by the State Key Laboratory of Coal Resources and Safe Mining, China University of Mining and Technology (No. SKLCRSM15X01) and the National Key Research and Development Plan (Grant No. 2017YFC0603001).

Li, Z., Chen, K., Li, Z., Huang, W., and Wang, X. (2021). Deterioration and Cavity of Surrounding Rocks at the Bottom of Tunnel under the Combined Action of Heavy-Haul Load and Groundwater. Exp. Study 9, 1177. doi:10.3389/feart.2021. 779578

Liu, E., Huang, R., and He, S. (2012). Effects of Frequency on the Dynamic Properties of Intact Rock Samples Subjected to Cyclic Loading under Confining Pressure Conditions. Rock Mech. Rock Eng. 45, 89-102. doi:10.1007/s00603011-0185-y

Liu, Y., Dai, F., Feng, P., and Xu, N.-w. (2018). Mechanical Behavior of Intermittent Jointed Rocks under Random Cyclic Compression with Different Loading Parameters. Soil Dyn. Earthquake Eng. 113, 12-24. doi:10.1016/j.soildyn.2018.05.030 Liu, W., Zhang, Z. X., Fan, J. Y., Jiang, D., Li, Z., and Chen, J. (2020a). Research on Gas Leakage and Collapse in the Cavern Roof of Underground Natural Gas Storage in Thinly Bedded Salt Rocks. J. Energ. Storage 31, 101669. doi:10.1016/j. est.2020.101669

Liu, W., Zhang, X., Fan, J. Y., Zuo, J. J., Zhang, Z., and Chen, J. (2020b). Study on the Mechanical Properties of Man-Made Salt Rock Samples with Impurities. J. Nat. Gas Sci. Eng. 84, 103683. doi:10.1016/j.jngse.2020.103683

Liu, B., Zhao, Y., Zhang, C., Zhou, J., Li, Y., and Sun, Z. (2021). Characteristic Strength and Acoustic Emission Properties of Weakly Cemented sandstone at Different Depths under Uniaxial Compression. Int. J. Coal Sci. Technol. 8, 1288-1301. doi:10.1007/s40789-021-00462-0

Madlener, R., and Specht, J. M. (2013). An Exploratory Economic Analysis of Underground Pumped-Storage Hydro Power Plants in Abandoned Coal Mines. SSRN Electron. J. doi:10.2139/ssrn.2350106

Menéndez, J., Ordóñez, A., Álvarez, R., and Loredo, J. (2019a). Energy from Closed Mines: Underground Energy Storage and Geothermal Applications. Renew. Sust. Energ. Rev. 108, 498-512. doi:10.1016/j.rser.2019.04.007

Menéndez, J., Loredo, J., Galdo, M., and Fernández-Oro, J. M. (2019b). Energy Storage in Underground Coal Mines in Nw spain: Assessment of an Underground Lower Water Reservoir and Preliminary Energy Balance. Renew. Energ. 134, 1381-1391. doi:10.1016/j.renene.2018.09.042

Menéndez, J., Schmidt, F., Konietzky, H., Fernández-Oro, J. M., Galdo, M., Loredo, J., et al. (2019c). Stability Analysis of the Underground Infrastructure for Pumped Storage Hydropower Plants in Closed Coal Mines. Tunnelling Underground Space Tech. 94, 103117. doi:10.1016/j.tust.2019.103117

Nejati, H. R., and Ghazvinian, A. (2014). Brittleness Effect on Rock Fatigue Damage Evolution. Rock Mech. Rock Eng. 47, 1839-1848. doi:10.1007/ s00603-013-0486-4

Peng, K., Zhou, J., Zou, Q., and Song, X. (2020). Effect of Loading Frequency on the Deformation Behaviours of Sandstones Subjected to Cyclic Loads and its 
Underlying Mechanism. Int. J. Fatigue 131, 105349. doi:10.1016/j.ijfatigue.2019. 105349

Rahman, M. M., Oni, A. O., Gemechu, E., and Kumar, A. (2020). Assessment of Energy Storage Technologies: A Review. Energ. Convers. Manag. 223, 113295. doi:10.1016/j.enconman.2020.113295

Roberts, L. A., Buchholz, S. A., Mellegard, K. D., and Düsterloh, U. (2015). Cyclic Loading Effects on the Creep and Dilation of Salt Rock. Rock Mech. Rock Eng. 48, 2581-2590. doi:10.1007/s00603-015-0845-4

Tang, J.-H., Chen, X.-D., and Dai, F. (2020). Experimental Study on the Crack Propagation and Acoustic Emission Characteristics of Notched Rock Beams under post-peak Cyclic Loading. Eng. Fracture Mech. 226, 106890. doi:10.1016/ j.engfracmech.2020.106890

Wang, Y., Gong, B., and Tang, C. (2021a). Numerical Investigation on Fracture Mechanisms and Energy Evolution Characteristics of Columnar Jointed Basalts with Different Model Boundaries and Confining Pressures. Front. Earth Sci. 9, 1098. doi:10.3389/feart.2021.763801

Wang, J. B., Zhang, Q., Song, Z. P., and Zhang, Y. (2021b). Experimental Study on Creep Properties of Salt Rock under Long-Period Cyclic Loading. Int. J. Fatigue 143, 106009. doi:10.1016/j.ijfatigue.2020.106009

Xiao, J.-Q., Ding, D.-X., Jiang, F.-L., and Xu, G. (2010). Fatigue Damage Variable and Evolution of Rock Subjected to Cyclic Loading. Int. J. Rock Mech. Mining Sci. 47, 461-468. doi:10.1016/j.ijrmms.2009.11.003

Yang, D. S., Qi, X. Y., Chen, W. Z., Wang, S. G., and Yang, J. P. (2018). Anisotropic Permeability of Coal Subjected to Cyclic Loading and Unloading. Int. J. Geomech. 18, 04018093. doi:10.1061/(asce)gm.1943-5622.0001229
Zhao, J., Konietzky, H., Herbst, M., and Morgenstern, R. (2021). Numerical Simulation of Flooding Induced Uplift for Abandoned Coal Mines: Simulation Schemes and Parameter Sensitivity. Int. J. Coal Sci. Technol. 8, 1238-1249. doi:10.1007/s40789-021-00465-x

Zhong, C., Zhang, Z., Ranjith, P. G., Lu, Y., and Choi, X. (2019). The Role of Pore Water Plays in Coal under Uniaxial Cyclic Loading. Eng. Geology. 257, 105125. doi:10.1016/j.enggeo.2019.05.002

Conflict of Interest: The authors declare that the research was conducted in the absence of any commercial or financial relationships that could be construed as a potential conflict of interest.

Publisher's Note: All claims expressed in this article are solely those of the authors and do not necessarily represent those of their affiliated organizations, or those of the publisher, the editors and the reviewers. Any product that may be evaluated in this article, or claim that may be made by its manufacturer, is not guaranteed or endorsed by the publisher.

Copyright $\odot 2022$ Zhili, Shengguo, Wenbing and Qingteng. This is an open-access article distributed under the terms of the Creative Commons Attribution License (CC $B Y$ ). The use, distribution or reproduction in other forums is permitted, provided the original author(s) and the copyright owner(s) are credited and that the original publication in this journal is cited, in accordance with accepted academic practice. No use, distribution or reproduction is permitted which does not comply with these terms. 